Check for updates

Cite this: RSC Adv., 2018, 8, 42032

Received 21st October 2018

Accepted 7th December 2018

DOI: $10.1039 / c 8 r a 08726 a$

rsc.li/rsc-advances

\section{Sludge degradation and microbial community structures analysis in a microbial electrolysis cell- coupled up flow anaerobic blanket reactor with an ultrasound treatment system}

\begin{abstract}
Youzhao Wang, † Yuan Pan, † Xianjin Li, Kuo Zhang and Tong Zhu (DD *
This study proposed a sludge degradation system comprised of: (i) an ultrasound treatment (UT) system to disintegrate sludge; (ii) an up flow anaerobic sludge blanket (UASB) reactor to degrade the disintegrated sludge; and (iii) a microbial electrolysis cell (MEC) in replacement of a three-phase UASB separator to deeply degrade the disintegrated sludge. The influence of the ultrasound power, the temperature, and the voltage on the sludge degradation process was discussed. The experimental results showed that the UT unit effectively promoted sludge disintegration, thereby leading to deterioration of the quality of the reactor effluent. The temperature and the voltage parameters were found to be key for the anaerobic degradation (AD) process within this system. The volatile suspended solid concentration in the effluent was maintained at $320-380 \mathrm{mg} \mathrm{L}^{-1}$ (ca. 0.08 times the raw sludge concentration), thereby validating the utilization of MEC as a three-phase separation unit. The total chemical oxygen demand removal was maintained at $61.3 \%$ during 5 days of AD upon intermittent exposure of the sludge to the UT unit, thereby showing that the system can effectively degrade solid organic matter. The bacterial community structure of the raw sludge significantly changed, with the high biodiversity of this system increasing the ecological stability. This system can degrade sludge with high efficiency and could be used in further engineering applications.
\end{abstract}

\section{Introduction}

Excess sludge pre-treatment followed by anaerobic digestion (AD) has been recognized as a promising technology to improve the efficiency of sludge degradation while enhancing the energy recovery. Ultrasound treatment (UT), owing to its strong physical and chemical effects on microorganisms, has been previously identified as a promising highly energy-consuming technology for sludge disintegration and improving digestion performance. ${ }^{\mathbf{1 , 2}}$ Both high- and low-density ultrasound can be applied in the same ultrasonic system owing to the unevenness of the ultrasonic density within the reactor. ${ }^{3}$ Elsayed and George reported superior degradation results for a food waste reactor internally exposed to UT ( 24 min per day) as compared to the values outside the reactor. ${ }^{4}$ Moreover, the utilization of UT in the $\mathrm{AD}$ process can facilitate the disintegration of solids while enhancing the effects of ultrasonic cavitation. ${ }^{5}$ Intermittent UT exposure achieved high degradation efficiency because both high and low density ultrasound radiations were applied within the same ultrasound system. Therefore, the utilization of

School of Mechanical Engineering and Automation, Northeastern University, Shenyang 110004, China

$\uparrow$ These authors contributed equally to this work and should be considered co-first authors. intermittent UT inside the sludge disintegration reactor was justified.

Up flow anaerobic sludge blanket (UASB) reactor have been considered one of the most effective anaerobic reactor for the digestion organic substances from various effluents. ${ }^{6}$ Thus, organic wastewaters with low solid suspension content were effectively degraded at high dilution rates by using a UASB reactor. Large amounts of organic matter were released from the sludge solid into the liquid phase, thereby rapidly deteriorating the quality of the sludge filtrate after every sludge treatment. $^{7}$ Thus, a USAB reactor might efficiently degrade the disintegrated sludge.

Microbial electrolysis cells (MEC) are bio-electrochemical systems developed from microbial fuel cells (MFC) that have been previously applied to accelerate the decomposition of organic pollutant molecules while generating an electric field as a result of the biological process. ${ }^{8}$ MFC treatment could improve both the rate and extent of organic matter degradation in sludge, particularly upon ultrasound pretreatment over the sludge. ${ }^{9}$ The insertion of a pair of electrodes into an anaerobic reactor resulted in highly efficient degradation of organics in wastewater via anaerobic fermentation combined with MEC electrode reaction. ${ }^{\mathbf{1 0}}$ This high performance resulted from: (i) the higher electron transfer for the organic matter degradation (i.e., organic oxidation generates electrons) upon utilization of 
anode biofilms; and (ii) the application of micro electric fields that increased the cellular metabolic function of the microorganisms. ${ }^{11,12}$ Liquid phase-installed electrodes in anaerobic hybrid systems were more efficient than those located in the sludge phase in AD-MEC degradation systems. In summary, the addition of a MEC unit can be used to enhance the AD efficiency of an anaerobic reactor. ${ }^{13}$

Recently, various sludge disintegration technologies have been developed for efficient sludge reduction or degradation. However, studies focused on high-efficiency sludge degradation processes with further engineering applications are scarce in the literature. This study proposed that utilization of UT to disintegrate sludge, the application of a UASB reactor to degrade the disintegrated sludge, and the replacement of a three-phase UASB separator with a MEC unit comprised of graphite fiber brush and titanium for deeply degrading of the disintegrated sludge. The valuable information obtained from this work would be useful for further development of sludge mineralization processes.

\section{Materials and methods}

\subsection{Sludge}

The raw sludge was collected from Shenshuiwan wastewater treatment plant, Shenyang, China. The anaerobic granular sludge was artificially cultivated in the laboratory. The characteristics of the raw sludge and anaerobic granular sludge were presented in Table 1.

\subsection{Sludge degradation system configuration}

Sludge disintegration was performed by an ultrasonic cell disruption system with the frequency of $20 \mathrm{kHz}$ and a probe of $\Phi 20$ mm (GM1200D, Shunmatech LTD, China). Because of the direction of complex cavitation processes near powerful ultrasound sources, the UT reactor was made by polymethyl methacrylate with a $10 \mathrm{~L}$ volume $(\Phi 20 \times 40 \mathrm{~cm})$. To reduce acoustic streaming and increase heterogeneous acoustic pressure to degrade sludge, a $1200 \mathrm{~W}$ ultrasonic probe was immersed $10 \mathrm{~mm}$ into the sludge.

The UASB was made of polymethyl methacrylate and possessed $35 \mathrm{~L}$ volume $(\Phi 14 \mathrm{~cm} \times 160 \mathrm{~cm})$. A single-chamber and membrane-less MEC was applied in the UASB. Both the anode and cathode electrodes of the MEC comprised graphite fiber brush $(\Phi 15 \mathrm{~cm} \times 20 \mathrm{~cm})$ and titanium wire, which were located at $1 / 2$ reactor depth. The distance between the brushes was $5-10 \mathrm{~cm}$. Electrode electricity was supplied by a regulated
DC power source through an electric wire. The temperature of sludge degradation system was maintained by heater band and $\mathrm{pH}$ value was maintained by the automatic control (Fig. 1).

\subsection{Sludge degradation system operation}

2.3.1 Start-up. Accordingly, $10 \mathrm{~L}$ of raw sludge was placed in the UT reactor, whereas $5 \mathrm{~L}$ of anaerobic granular sludge and $30 \mathrm{~L}$ of raw sludge were added to the UASB-MEC reactor. The ultrasonic cell disruption system in the UT reactor was operated for 10 min per day. A magnetic stirrer was used to continuously stir the sludge at $100 \mathrm{rpm}$. Sludge (20\%) was replaced by new raw sludge every day. In the UASB reactor, $80 \%$ of the sludge flowed reversely through "E1", and the flow rate of "E2" was $5 \mathrm{~L}$ per day (Fig. 1). The MEC was supplied with $0.5 \mathrm{~V}$, and the sludge degradation system maintained at temperature of $35{ }^{\circ} \mathrm{C}$ and $\mathrm{pH}$ value 7.5-8.0. The SCOD, protein, and VSS in the effluent through the "E2" gradually stabilized after 30 days. The MEC achieved $0.5 \mathrm{~V}$ and $45 \mathrm{~mA}$ (resistance $=11.2 \Omega$ ). The operation was then terminated.

2.3.2 Experimental process. All sludge samples (10 L) were replaced by fresh raw sludge samples in the UT reactor. AD was performed by sequencing batch reactors with a system response time of 8 days. A batch of experiments in UASB, MEC, UT-UASB, UASB-MEC, and UT-UASB-MEC reactor configurations was carried out as control at a temperature of $35{ }^{\circ} \mathrm{C}$, a voltage of $0.5 \mathrm{~V}$, and a UT time of $10 \mathrm{~min}$ per day. The influence of the ultrasound time (i.e., 0,10 , and $20 \mathrm{~min}$ per day), the temperature (i.e., 15,35 , and $55^{\circ} \mathrm{C}$ ), and the voltage (i.e., 0.2, 0.5, and 0.8 V) on the sludge degradation process within the UT-UASB-MEC system was studied while maintaining the rest of conditions unchanged.

The sludge disintegration and degradation characteristics of the UT-UASB-MEC degradation system were evaluated using SCOD, protein and VSS concentrations. The bacterial community structure (control) in the UT-UASB-MEC system was further analyzed based on the degradation characteristics. No gas analysis was carried out because of the difficulties of performing gas concentration measurements in our laboratory.

The experiments were conducted in duplicate, and the average values were reported.

\subsection{Energy efficiency $\left(E_{\mathrm{e}}\right)$}

The energy consumption during sludge degradation is significantly important. Thus, $E_{\mathrm{e}}$ (eqn (1)) was introduced to evaluate the energy consumption during sludge degradation in the

Table 1 Characteristics of the raw sludge and anaerobic granular sludge

\begin{tabular}{lrr}
\hline Parameters & Raw sludge & Anaerobic sludge \\
\hline Suspended solid (SS, $\left.\mathrm{mg} \mathrm{L}^{-1}\right)$ & $5320 \pm 50$ & $17420 \pm 50$ \\
Volatile suspended solid (VSS, $\left.\mathrm{mg} \mathrm{L}^{-1}\right)$ & $4210 \pm 50$ & $5450 \pm 50$ \\
Total chemical oxygen demand (TCOD, $\left.\mathrm{mg} \mathrm{L}^{-1}\right)$ & $6275.3 \pm 127.5$ & $7825.8 \pm 127.5$ \\
Soluble chemical oxygen demand (SCOD, $\left.\mathrm{mg} \mathrm{L}^{-1}\right)$ & $127.5 \pm 27.5$ & $3275.6 \pm 27.5$ \\
Protein $\left(\mathrm{mg} \mathrm{L}^{-1}\right)$ & $29.3 \pm 5.2$ & $185.7 \pm 5.3$ \\
Soluble carbohydrate $\left(\mathrm{mg} \mathrm{L}^{-1}\right)$ & $31.4 \pm 2.8$ & $153.8 \pm 3.1$
\end{tabular}




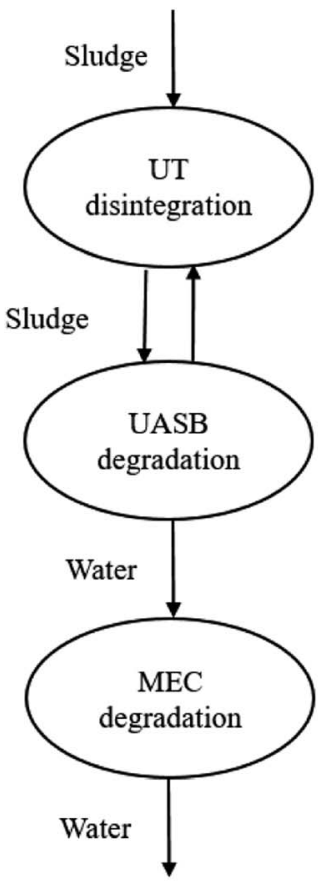

a

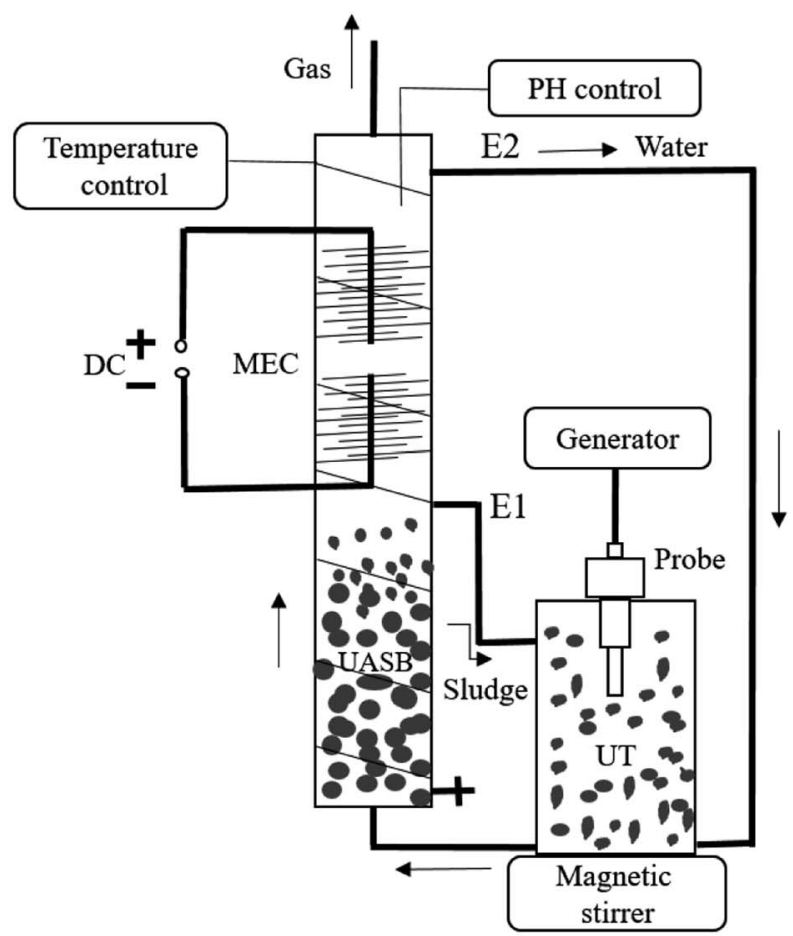

b

Fig. 1 UT-UASB-MEC degradation system: (a) flow chart; (b) schematics.

evaluation of the overall process (i.e., the input electrical power of the MEC unit was ignored). Since the effect of UT on the $\Delta$ TCOD change from solid sludge was negligible, the last ultrasound consumption was not accounted for.

$$
E_{\mathrm{e}}=\frac{1000 \times P \times t}{\left(\mathrm{TCOD}_{0}-\mathrm{TCOD}\right) \times V}
$$

where $E_{\mathrm{e}}$ is the energy efficiency $\left(\mathrm{kJ} \mathrm{kg}^{-1}\right), \mathrm{TCOD}_{0}$ is the TCOD of raw sludge in the UT reactor $\left(\mathrm{mg} \mathrm{L}^{-1}\right)$, TCOD is TCOD of the treated sludge in the system $\left(\mathrm{mg} \mathrm{L}^{-1}\right), V$ is the sludge volume (L), P is the electrical power of the UT unit (W) and $t$ is the UT time (s).

\subsection{Analytical methods}

The sludge sample was centrifuged at $9000 \mathrm{rpm}$ for $10 \mathrm{~min}$ with a centrifuge (3H16RI, Hersey LTD, China), and then filtered with a $0.45 \mu \mathrm{m}$ filter membrane. The filtered was used to measure SCOD, protein. The sludge was treated with $0.5 \mathrm{~mol} \mathrm{~L}^{-1} \mathrm{NaOH}$ for $22 \mathrm{~h}$, and the filtered was sampled to determine TCOD. $^{1}$ VSS, SCOD and TCOD of sludge was measured according to the APHA Methods. ${ }^{14,15}$ Protein analysis was a simple accurate method for the quantitative assessment of sewage sludge disintegration, ${ }^{16}$ and protein was measured according to Folin-phenol method. ${ }^{17}$ Soluble carbohydrate concentration was determined according to the phenol-sulfuric acid method. ${ }^{18}$

Pyrosequencing is a widely-used molecular biological technology, used in environmental science fields to study functional microbial communities. ${ }^{19}$ In this study, bacterial community structures and the relative abundance of species were analyzed using cloning sequencing analysis. Bacteria abundance was quantified using real-time polymerase chain reaction (PCR). The primer sets 338F (5'-ACTCCTACGGGAGGCAGCA- $\left.3^{\prime}\right)$ and 806R (5'-GGACTACHVGGGTWTCTAAT- $\left.3^{\prime}\right)$ of 16S rRNA were used to target all bacteria (sourced from Shanghai (China) Majorbio Bio-pharm Technology Co., Ltd.).

\section{Results and discussion}

\subsection{Influence of the ultrasound treatment on the sludge degradation process}

The influence of the ultrasound treatment on the sludge degradation process is summarized in Fig. 2 and Table 2. The SCOD, protein, carbohydrate and VSS concentrations remained nearly unchanged after the first three days. The sludge hydrolysis limited the rate and extent of organic degradation in the AD process. ${ }^{1}$ The SCOD, protein and carbohydrate concentration rapidly increased upon UT application at the extent of the VSS concentration, indicating that UT effectively released the organic components from the sludge solid phase to the liquid phase. ${ }^{19}$ The SCOD, protein and carbohydrate concentration gradually increased with $\mathrm{AD}$ time (i.e., cumulative UT time increases), while the VSS concentration decreased gradually. This might be produced by the gradually lower levels of organic matter in the solid sludge that led to lower dissolution rates of the sludge. After 8 days of AD, the SCOD, protein, carbohydrate 

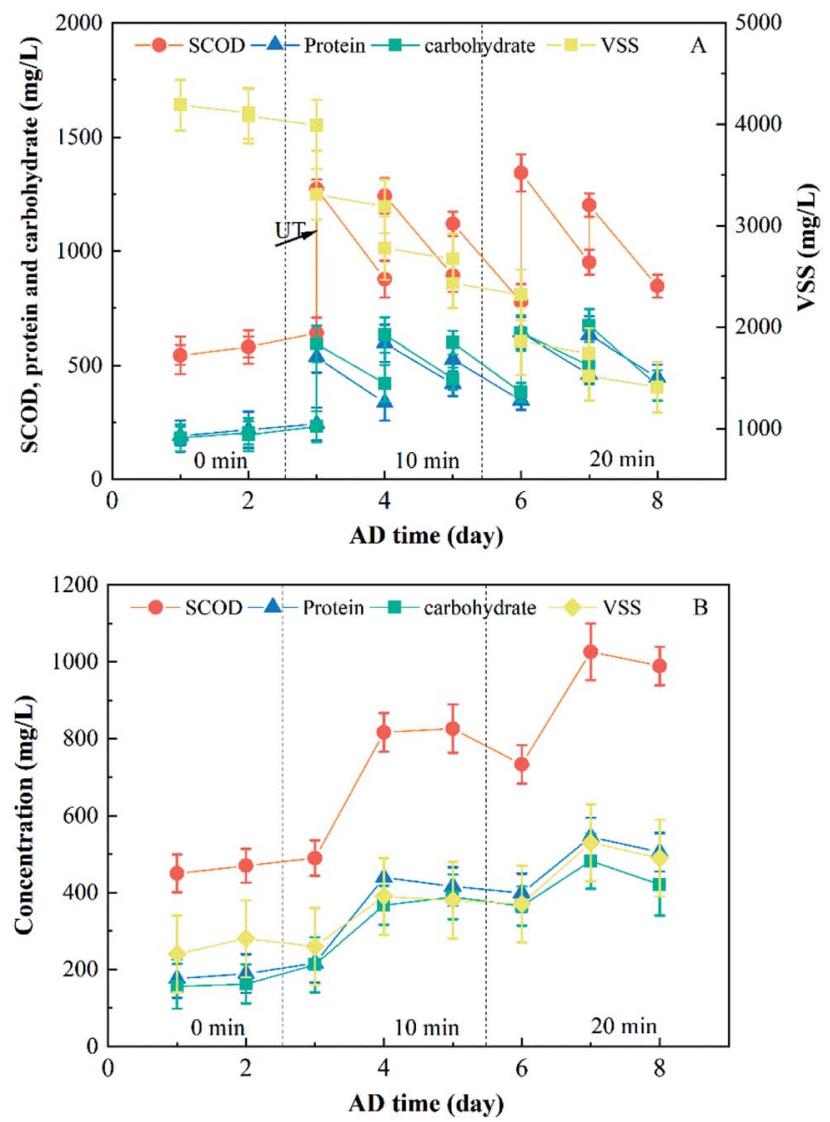

Fig. 2 Influence of the ultrasound treatment on the sludge degradation process: (A) characteristics of the sludge in the UT reactor; (B) characteristics of the sludge in the effluent of the system.

Table 2 TCOD removal in the UT reactor and $E_{\mathrm{e}}$ change values

\begin{tabular}{lll}
\hline AD time (day) & TCOD removal (\%) & $E_{\mathrm{e}}\left(\mathrm{kJ} \mathrm{kg}^{-1}\right)$ \\
\hline 2 & 5.2 & 0 \\
5 & 51.7 & 66000 \\
8 & 74.8 & 107000
\end{tabular}

and VSS concentration in the UT reactor reached 846.9, 445.9, 412.5 and $1410.9 \mathrm{mg} \mathrm{\textrm {L } ^ { - 1 }}$, respectively. Thus, these results indicate that the efficiency of the anaerobic hydrolysis was enhanced by ultrasonic disintegration, with gas production being improved by the UASB-MEC reactor during the $\mathrm{AD}$ process. The SCOD, protein, carbohydrate and VSS concentration in the effluent noticeably increased with the UT time (from 10 to 20 min per day) as a result of the larger amounts of organic matter and float sludge upon intermittent UT. 7.

Table 2 shows the TCOD removal values in the UT reactor and the $E_{\mathrm{e}}$ change. TCOD removal gradually increased and the increasement of $E_{\mathrm{e}}$ noticeably decreased with UT (cumulative) time. These results can be explained in base of a gradually higher difficulty for sludge disintegration with decreasing organic matter levels in the solid sludge. Some studies have shown that low intensity ultrasound can promote the activity of enzymes, cell growth and cell membrane permeability. ${ }^{20,21}$ Xie and Wang applied the low intensity ultrasound to enhance phosphorus removal in biological systems and found the dehydrogenase activity increased by $50 \%$ after ultrasonic irradiation for $4 \mathrm{~h}^{22}$ The anaerobic biodegradability of sewage sludge increased by $67.6 \%$ after treating by low intensity ultrasound. ${ }^{23}$ The enzymatic activity effectively increased in the region of low ultrasonic density within the UT reactor by stimulating the metabolic activities inside the cells comprising the anaerobic sludge. Thus, UT can disintegrate the sludge and thus accelerate the degradation of organic matter in the sludge.

\subsection{Influence of the temperature on the sludge degradation process}

The influence of the temperature on the sludge degradation process was significant owing to maintaining high biomass concentrations at the bottom of the UASB reactor in form of aggregated granular sludge. ${ }^{24}$ The degradation of organic pollutants differ significantly for thermophilic $\left(55^{\circ} \mathrm{C}\right)$, mesophilic $\left(35^{\circ} \mathrm{C}\right)$, and low temperature (below $\left.15{ }^{\circ} \mathrm{C}\right)$ microorganism. ${ }^{6}$ Therefore, the influence of the temperature on the sludge degradation process within the UASB reactor unit and this system was analyzed.

Theoretical VSS data (i.e., VSS data measured for 0.8 times) in the effluent was used since $80 \%$ of the sludge flowed reversely through "E1". The influence of the temperature on the sludge degradation process is summarized in Fig. 3 and Table 3. The SCOD, protein and carbohydrate concentration increased at the expense of the VSS concentration after the first day. This might result from the continuous dissolving of the disintegrated sludge in combination with the degradation of the dissolved organic matter to biogas during the upward flow process. And the dissolution rate was higher than the degradation rate in the UASB reactor. Then The SCOD, protein, carbohydrate and VSS concentration gradually decreased as a result of a steady decrease in the dissolution rate of solid sludge, and this dissolution rate was lower than the degradation rate of the soluble organic matter in this system. The SCOD, protein and carbohydrate concentration in the UASB reactor unit were $542.8,365.1$ and $301.2 \mathrm{mg} \mathrm{L}^{-1}$, respectively, after 8 days of $\mathrm{AD}$ because of the inherent limitations of the anaerobic treatment. Therefore, the UASB reactor unit can be used to degrade the disintegrated sludge downstream the UT reactor, although further improvements are required in the degradation process.

According to our calculations, the influence of the temperature on the sludge degradation process in the MEC reactor was negligible, with VSS concentration in the effluent remaining at 320-380 $\mathrm{mg} \mathrm{L}^{-1}$ (ca. 0.08 times of the raw sludge concentration). There was a phenomenon that the biogas bubbles produced in the UASB and MEC units were separated from the disintegrated sludge by the graphite brush of the MEC. Thus, the graphite and titanium brush of the MEC unit achieved three-phase separation.

SCOD decreased 25.4, 70.7, and $92.9 \mathrm{mg} \mathrm{L}^{-1}$ at temperatures of 15,35 , and $55{ }^{\circ} \mathrm{C}$, respectively, after the UASB reactor unit (i.e., the second day after changing the conditions). $E_{\mathrm{e}}$ reached $1.11,1.05$, and 1.01 times that of the control after 2,5 , and 8 days of $\mathrm{AD}$, respectively (Table 3 ). The above results show that 

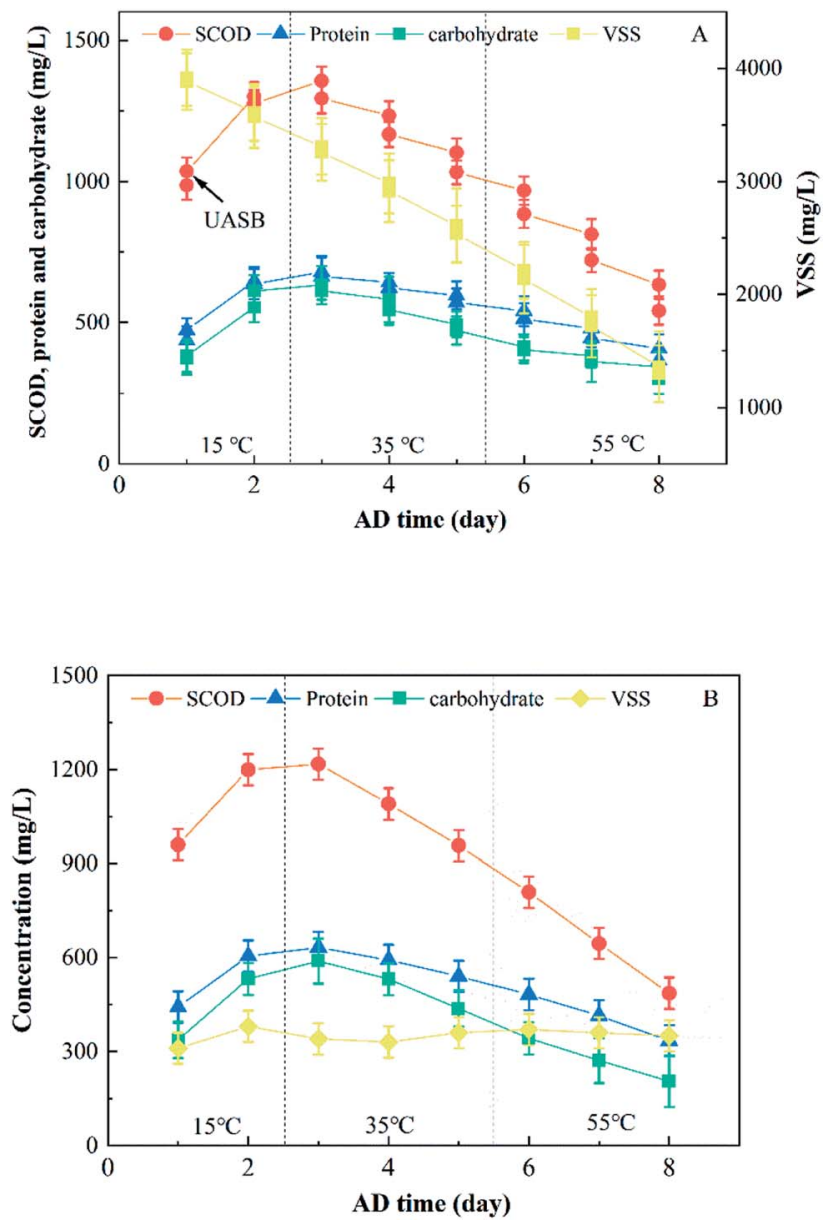

Fig. 3 Influence of the temperature on the sludge degradation process: (A) characteristics of the sludge in UASB reactor; (B) characteristics of the sludge in the effluent of the system.

Table 3 TCOD removal in the UT reactor and $E_{\mathrm{e}}$ change values

\begin{tabular}{lll}
\hline AD time (day) & TCOD removal (\%) & $E_{\mathrm{e}}\left(\mathrm{kJ} \mathrm{kg}^{-1}\right)$ \\
\hline 2 & 24.1 & 95000 \\
5 & 57.6 & 99000 \\
8 & 70.3 & 114000
\end{tabular}

the degradation rate of organic matter rapidly increases with temperature. Thus, temperature is a key parameter affecting the $\mathrm{AD}$ process in this system.

\subsection{Influence of the voltage on the sludge degradation process}

Zhang et al., 2015 reported that higher voltage values accelerate the degradation of organic matter during a period of three days. ${ }^{25}$ The typical anode potential of a MEC unit as a result of the oxidation of the organic matter by the bacteria was $c a .0 .5 \mathrm{~V}$. Thus, the influence of the voltage on the sludge degradation in the MEC reactor unit was analyzed.

The characteristics of the sludge in the MEC reactor unit are summarized in Fig. 4 and Table 4 . Since the VSS concentration

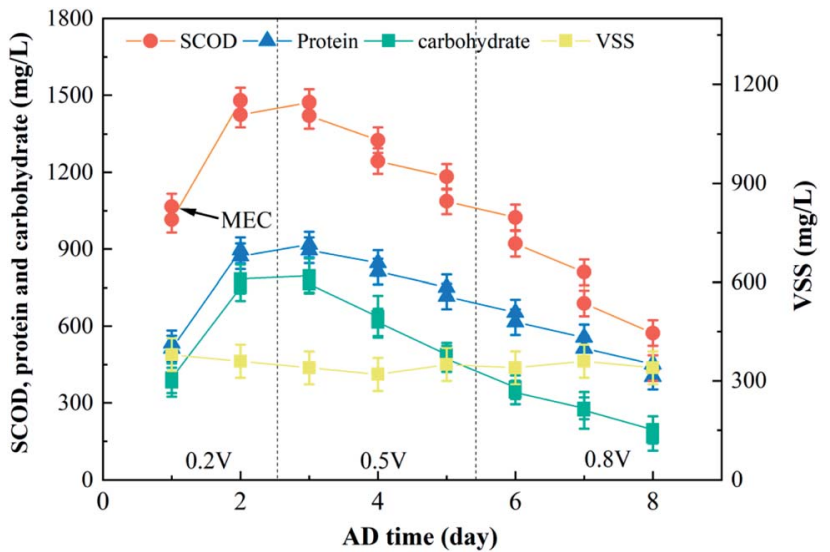

Fig. 4 Influence of the voltage on the sludge degradation process: characteristics of the sludge in the MEC reactor.

Table 4 TCOD removal in the UT reactor and $E_{\mathrm{e}}$ change values

\begin{tabular}{lll}
\hline AD time (day) & TCOD removal $(\%)$ & $E_{\mathrm{e}}\left(\mathrm{kJ} \mathrm{kg}^{-1}\right)$ \\
\hline 2 & 25.9 & 88000 \\
5 & 60.7 & 94000 \\
8 & 71.1 & 113000 \\
\hline
\end{tabular}

in the inflow of the MEC unit was hardly measured, Fig. 4 only showed the VSS concentration in the effluent. The SCOD, protein and carbohydrate concentration significantly decreased downstream the MEC reactor, thereby revealing that this unit was effective in degrading a large fraction of the organic matter dissolved from the solid sludge (e.g., aromatic proteins and soluble microbial byproducts) ${ }^{26}$ The SCOD, protein, carbohydrate and VSS concentrations in the effluent reached 436.5, 403.1, 165.2 and $340.1 \mathrm{mg} \mathrm{L}^{-1}$, respectively, after 8 days of AD. These results suggested that electrochemically active microbes were adsorbed on the surface of the anode and subsequently reproduced as a result of the oxidation (i.e., loss of electrons) of the soluble organic matter. Additionally, this degradation system was a useful technology for the degradation of proteins. ${ }^{27}$

SCOD decreased $54.7,96.6$, and $136.1 \mathrm{mg} \mathrm{L}^{-1}$ at voltages of $0.2,0.5$, and $0.8 \mathrm{~V}$, respectively, after the MEC reactor unit (i.e., the second day after changing the conditions). These results indicate that the degradation rate of organic matter significantly increase with voltage. The influence of the voltage on $E_{\mathrm{e}}$ was similar to that of temperature, and this might be explained by a larger electron transfer during the degradation of the organic matter as a result of the utilization of the anode biofilm (Table 4). Additionally, the application of a micro-electric field could result in an increase of the cellular metabolic function of the microorganisms. ${ }^{11}$ Thus, the voltage was also a key parameter affecting the $\mathrm{AD}$ process in this system.

The TCOD removal values for various methods are compared in Table 5. Remarkably, the TCOD removal of the MFC unit was greater than that of conventional $\mathrm{AD}$, while the utilization of the UT unit (i.e., UT-MFC) increased the sludge TCOD removal as compared to the single MFC. TCOD removal of the UT-MFC 
Table 5 Comparison of TCOD removal values for different reactor configurations

\begin{tabular}{lllll}
\hline No. & Operation method & AD time (day) & TCOD removal (\%) & Ref. \\
\hline 1 & MFC & 15 & 40.8 & Zhang et al., 2012 \\
2 & Conventional AD & 6 & 13.8 & Jiang et al., 2010 \\
3 & MFC & 6 & 19.2 & Jiang et al., 2011 \\
4 & Conventional AD & 5 & 19.2 & Jiang et al., 2009 \\
5 & MFC & 5 & 57 & This study \\
6 & UT-conventional AD & 5 & 25.8 & 36.7 \\
7 & UT-MFC & 5 & 12.5 & 22.6 \\
8 & Conventional AD & 6 & 31.7 & 23.1 \\
9 & UT-MFC & 5 & 61.3 & \\
11 & UASB & 5 & 5 & \\
13 & MEC & 5 & 5 &
\end{tabular}

coupled system was greater than that of conventional UT-AD. Herein, TCOD removal of the MEC unit was greater than that of UASB, and, again, the UT unit increased the TCOD removal of UASB. TCOD removal reached $61.3 \%$ for the UT-UASB-MEC integrated system upon intermittent UT of the sludge (total energy of $360 \mathrm{~kJ} \mathrm{~L}^{-1}$ ) after 5 days of AD. TCOD removal reached $57 \%$ for the UT-MFC system after ultrasound treating the sludge (total energy $>720 \mathrm{~kJ} \mathrm{~L}^{-1}$ ) for the first 5 days of AD. ${ }^{9}$ Thus, the electrodes installed in the liquid phase of this anaerobic hybrid system can explain these results since this system showed lower resistance as compared to other configurations. ${ }^{28}$ The low molecular weight substrate derived from the UASB reactor unit was efficiently degraded. Thus, the UT-UASB-MEC integrated degradation system was an effective technology for the degradation of solid organic matter.

\subsection{Comparative analysis based on pyrosequencing of bacterial communities}

3.4.1 Richness and biodiversity of bacteria phylotypes. The richness and diversity of the bacterial communities are shown in Table 6. The number of operational taxonomic units (OTU) obtained by pyrosequencing of raw sludge, treated sludge, biological cathode, and cathode were $480,850,829$, and 882 , respectively. New bacterial phylotypes continued to emerge even after 15000 sequences sampling (i.e., pyrosequencing was based on the OTU at a 3\% distance, Fig. 5). Simultaneously, richness estimates (Ace and Chao 1) and diversity (Shannon) index measurements indicated that the microbial community of the anaerobic sludge (i.e., biological cathode and anodic) was richer than that of raw sludge. Since high biodiversity increases the ecological stability, ${ }^{29}$ this system has a higher capacity to resist environmental stress.

Table 6 Richness and diversity of bacterial communities

\begin{tabular}{lllll}
\hline Sample & OTUs & Ace & Chao 1 & Shannon \\
\hline Raw sludge & 480 & 498 & 504 & 4.95 \\
Treated sludge & 850 & 921 & 925 & 5.35 \\
Cathode & 829 & 883 & 892 & 5.44 \\
Anodic & 882 & 933 & 956 & 5.33
\end{tabular}

3.4.2 Bacterial community comparisons. The principal component (PCA) and Venn analyses were used to identify the differences among the bacterial community structures (Fig. 6). The principal components 1 (PC1) and 2 (PC2) were extracted and accounted for 55.17 and $31.22 \%$ of the total community variations, respectively (Fig. 6a). These results suggested clear distinctions among these four samples despite they shared the same source of microbial consortia. The sum of total observed OTU in the samples was 1015 , although only 277 OTU were shared among these tests (Fig. 6b). The majority of the shared OTU were Proteobacteria (49.4\%), Bacteroidetes (17.6\%), Actinobacteria (11.5\%), and Firmicutes $(6.1 \%)$. This result revealed that the raw sludge changed significantly as a result of the ultrasonic disintegration and $\mathrm{AD}$ processes. The shared OTU between the treated sludge, and the biological cathode and anode of the MEC unit were 710 (i.e., the sum of the total observed OTU was 962). This result revealed a selective enrichment of the anode and cathode from the anaerobic sludge, this leading to extremely high similarity.

3.4.3 Bacterial taxonomy analyses. The analyses of the microbial community structures comprising the system were quite necessary to understand the sludge degradation process. Fig. 7 shows the taxonomic classification of the dominant

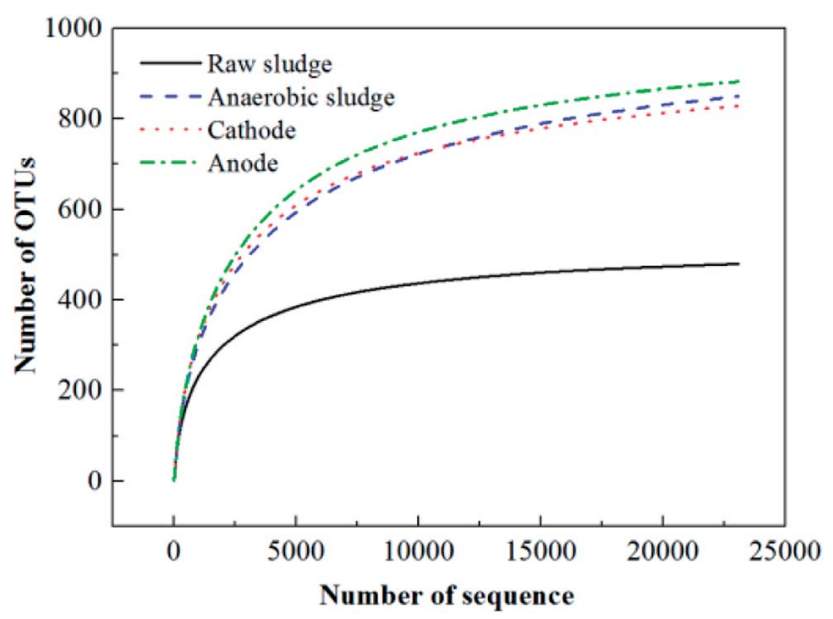

Fig. 5 Rarefaction curves based on pyrosequencing of bacterial communities. 


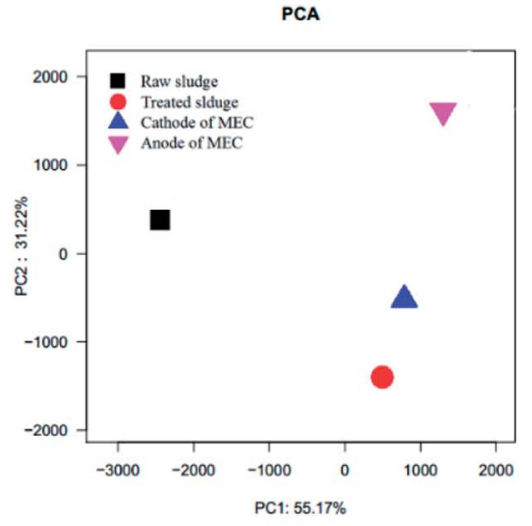

a
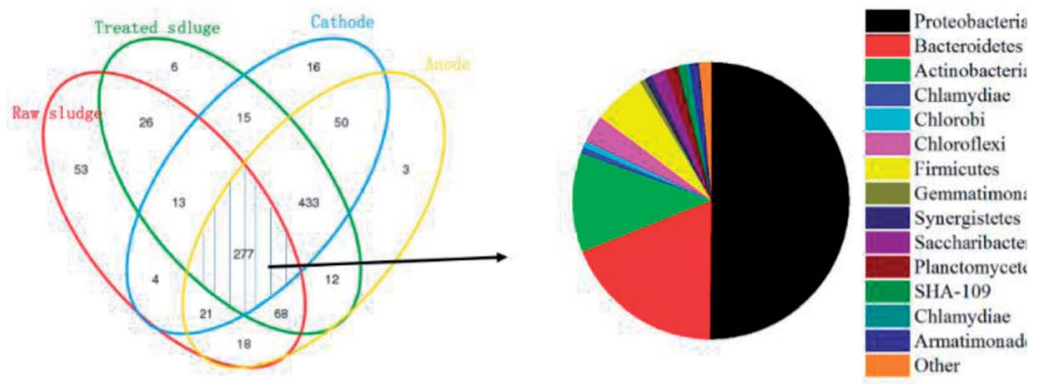

$\mathrm{b}$

Fig. 6 Comparative analysis of the bacterial communities based on pyrosequencing of the 16S rRNA gene: (a) PCA analysis; (b) Venn analysis.

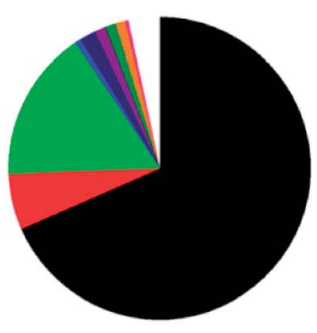

a

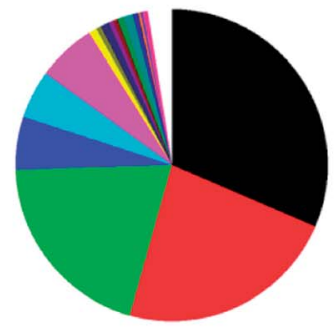

b

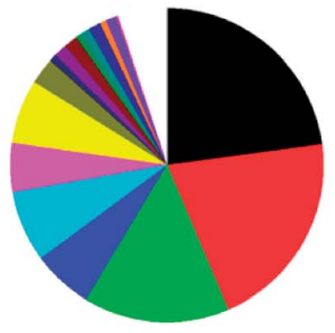

c

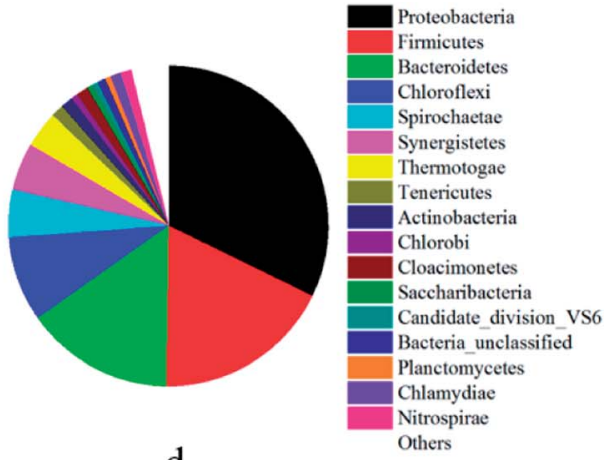

d

Fig. 7 Taxonomic classification of the dominant phylogenetic groups at the phylum level: (a) raw sludge; (b) treated sludge; (c) cathode; and (d) anode. Phyla groups with a relative abundance of less than $1 \%$ of the total composition were defined as "other".

phylogenetic groups from raw, treated sludge, biological cathode, and biological anode. The dominant species in the raw sludge were Proteobacteria, Bacteroidetes, and Firmicutes, accounting for $68.44,16.14$, and $5.97 \%$ of the sample, respectively. This result was consistent with Yang ${ }^{30}$ who used PCRdenatured gradient gel electrophoresis technology. After 8 days of operation, the dominant species in the sludge were Proteobacteria (31.47\%), Firmicutes (22.86\%), and Bacteroidetes (20.18\%). The increase of abundances of Firmicutes and Bacteroidetes maybe contributed by applying power supply. Firmicutes and Bacteroidetes have been reported to be a major group in many reported microbial fuel cell. ${ }^{31}$ The above results showed that $\mathrm{UT},{ }^{19} \mathrm{AD}^{32}$ and applying power supply led to the significant changes in the bacterial community structure of sludge. After applying power supply, the anode biofilm had significantly increased abundances of Firmicutes and Bacteroidetes. Bacteroidetes were found often in many bioelectrochemical system. ${ }^{15}$ The significant increase in Firmicutes might be attributed to its potential ability for electron transfer processes in MFC, as confirmed by Wrighton. ${ }^{29}$ Additionally, Firmicutes were known to play a critical role in the anaerobic hydrolysis and acidification process. ${ }^{33}$ Chloroflexi, Spirochaetae, and Synergistetes also significantly increased with operation time. Chloroflexi might have specialized in polysaccharide and protein degradation, while Spirochaetae and Synergistetes might obligate anaerobes to be introduced by vaccination and then proliferated over time. Thermotogae significantly increased on the bioelectrodes of the MEC unit, and this might accelerate the degradation efficiency of the treated sludge in this system. Cathode and anode bacteria accounted for 6.6 and $3.7 \%$ of the total, respectively. Bacteria mutation and rapid proliferation under micro electric fields and uneven heating conditions (i.e., heater band) might explain this result.

\section{Conclusions}

This study proposed a MEC-coupled UASB reactor provided with a UT system. UT effectively promoted sludge disintegration, although it deteriorated the quality of the reactor effluent. The UASB reactor unit was used to degrade the disintegrated sludge, and temperature was found to be a key parameter during sludge degradation. VSS concentration in the effluent was maintained at $320-380 \mathrm{mg} \mathrm{L}^{-1}$ ( $c a$. 0.08 times of the raw sludge concentration), thereby showing that the three-phase separator in the UASB reactor could be replaced with a MEC unit composed of graphite fiber brush and titanium. MEC achieved further 
degradation of the disintegrated sludge, and the influence of the voltage on the sludge degradation process was significant. The TCOD removal of the UT-UASB-MEC integrated system reached $61.3 \%$ when the sludge was intermittently ultrasound treated (total energy of $360 \mathrm{~kJ} \mathrm{~L}^{-1}$ ) during 5 days of $\mathrm{AD}$. Thus, this system could be used to effectively degrade solid organic matter.

The bacterial community structure of the raw sludge changed significantly in this system. Thus, the observed high biodiversity of this system could increase the ecological stability. Since ultrasound achieved sludge disintegration while accelerating its degradation, the $\mathrm{AD}$ and anodic oxidation processes in combination with an installed electric field improved the sludge degradation process. This study has a noticeable significance as it could increase the efficiency of the sludge anaerobic degradation process in engineering applications.

\section{Conflicts of interest}

There are no conflicts to declare.

\section{Acknowledgements}

This work was supported by the National Natural Science Foundation of China (51178089), the Doctoral Scientific Fund Project of China (20130042110009), and the Fundamental Research Funds for the Central Universities (N140306001, N1503040016).

\section{References}

1 A. Tiehm, K. Nickel, M. Zellhorn and U. Neis, Ultrasonic waste activated sludge disintegration for improving anaerobic stabilization, Water Res., 2001, 35, 2003-2009.

2 S. Pilli, P. Bhunia, S. Yan, R. LeBlanc, R. Tyagi and R. Surampalli, Ultrasonic pretreatment of sludge: a review, Ultrason. Sonochem., 2011, 18, 1-18.

3 S. Dähnke, K. Swamy and F. Keil, Modeling of threedimensional pressure fields in sonochemical reactors with an inhomogeneous density distribution of cavitation bubbles: comparison of theoretical and experimental results, Ultrason. Sonochem., 1999, 6, 31-41.

4 E. Elbeshbishy and G. Nakhla, Comparative study of the effect of ultrasonication on the anaerobic biodegradability of food waste in single and two-stage systems, Bioresour. Technol., 2011, 102, 6449-6457.

5 X. Li, T. Zhu, K. Zhang, L. Lv, T. Chai, Y. Shen, Y. Wang, M. You and Y. Xie, Effect of the sequence ultrasonic operation on anaerobic degradation of sewage sludge, Int. Biodeterior. Biodegrad., 2016, 112, 66-71.

6 R.-E. Yaya-Beas, E.-A. Cadillo-La-Torre, K. Kujawa-Roeleveld, J. B. Van Lier and G. Zeeman, Presence of helminth eggs in domestic wastewater and its removal at low temperature UASB reactors in Peruvian highlands, Water Res., 2016, 90, 286-293.
7 A. R. Mohammadi, N. Mehrdadi, G. N. Bidhendi and A. Torabian, Excess sludge reduction using ultrasonic waves in biological wastewater treatment, Desalination, 2011, 275, 67-73.

8 Y. Pan, Y. Wang, A. Zhou, A. Wang, Z. Wu, L. Lv, X. Li, K. Zhang and T. Zhu, Removal of azo dye in an up-flow membrane-less bioelectrochemical system integrated with bio-contact oxidation reactor, Chem. Eng. J., 2017, 326, 454461.

9 J. Jiang, Q. Zhao, L. Wei, K. Wang and D.-J. Lee, Degradation and characteristic changes of organic matter in sewage sludge using microbial fuel cell with ultrasound pretreatment, Bioresour. Technol., 2011, 102, 272-277.

10 B. Tartakovsky, P. Mehta, J. S. Bourque and S. R. Guiot, Electrolysis-enhanced anaerobic digestion of wastewater, Bioresour. Technol., 2011, 102, 5685-5691.

11 V. Sánchez-Vázquez, I. Gonzalez and M. Gutierrez-Rojas, Electric field as pretreatment to enhance the activity of a whole-cell biocatalyst for hydrocarbon degradation in contaminated water, Chem. Eng. J., 2015, 260, 37-42.

12 Y. Jiang, M. Su and D. Li, Removal of sulfide and production of methane from carbon dioxide in microbial fuel cellsmicrobial electrolysis cell (MFCs-MEC) coupled system, Appl. Biochem. Biotechnol., 2014, 172, 2720-2731.

13 D. Call and B. E. Logan, Hydrogen production in a single chamber microbial electrolysis cell lacking a membrane, Environ. Sci. Technol., 2008, 42, 3401-3406.

14 A. A. Wef, Standard methods for the examination of water and wastewater, Washington, DC, 1998.

15 Y. Wang, Y. Pan, T. Zhu, A. Wang, Y. Lu, L. Lv, K. Zhang and Z. Li, Enhanced performance and microbial community analysis of bioelectrochemical system integrated with biocontact oxidation reactor for treatment of wastewater containing azo dye, Sci. Total Environ., 2018, 634, 616-627.

16 U. Schmitz, C. R. Berger and H. Orth, Protein analysis as a simple method for the quantitative assessment of sewage sludge disintegration, Water Res., 2000, 34, 3682-3685.

17 L. A. Elson and W. T. J. Morgan, A colorimetric method for the determination of glucosamine and chondrosamine, Biochem. J., 1933, 27, 1824.

$18 \mathrm{~L}$. Webb, An investigation into the occurrence of sewage fungus in rivers containing papermill effluents-II. Chemical analysis of mill effluents, Water Res., 1985, 19, 955-959.

19 Y. Liu, X. Li, X. Kang, Y. Yuan, M. Jiao, J. Zhan and M. Du, Effect of extracellular polymeric substances disintegration by ultrasonic pretreatment on waste activated sludge acidification, Int. Biodeterior. Biodegrad., 2015, 102, 131-136.

20 M. Delgado-Povedano and M. L. de Castro, A review on enzyme and ultrasound: a controversial but fruitful relationship, Anal. Chim. Acta, 2015, 889, 1-21.

21 W. G. Pitt and S. A. Ross, Ultrasound increases the rate of bacterial cell growth, Biotechnol. Prog., 2003, 19, 1038-1044.

22 B. Xie, L. Wang and H. Liu, Using low intensity ultrasound to improve the efficiency of biological phosphorus removal, Ultrason. Sonochem., 2008, 15, 775-781. 
23 C. Liu, B. Xiao, A. Dauta, G. Peng, S. Liu and Z. Hu, Effect of low power ultrasonic radiation on anaerobic biodegradability of sewage sludge, Bioresour. Technol., 2009, 100, 6217-6222.

24 C. M. Martínez, L. B. Celis and F. J. Cervantes, Immobilized humic substances as redox mediator for the simultaneous removal of phenol and Reactive Red 2 in a UASB reactor, Appl. Microbiol. Biotechnol., 2013, 97, 9897-9905.

25 J. Zhang, Y. Zhang and X. Quan, Bio-electrochemical enhancement of anaerobic reduction of nitrobenzene and its effects on microbial community, Biochem. Eng. J., 2015, 94, 85-91.

26 J. Jiang, Q. Zhao, L. Wei and K. Wang, Extracellular biological organic matters in microbial fuel cell using sewage sludge as fuel, Water Res., 2010, 44, 2163-2170.

27 L. Lu, D. Xing, T. Xie, N. Ren and B. E. Logan, Hydrogen production from proteins via electrohydrogenesis in microbial electrolysis cells, Biosens. Bioelectron., 2010, 25, 2690-2695.

28 Q. Yin, X. Zhu, G. Zhan, T. Bo, Y. Yang, Y. Tao, X. He, D. Li and $Z$. Yan, Enhanced methane production in an anaerobic digestion and microbial electrolysis cell coupled system with co-cultivation of Geobacter and Methanosarcina, J. Environ. Sci., 2016, 42, 210-214.
29 K. C. Wrighton, P. Agbo, F. Warnecke, K. A. Weber, E. L. Brodie, T. Z. DeSantis, P. Hugenholtz, G. L. Andersen and J. D. Coates, A novel ecological role of the Firmicutes identified in thermophilic microbial fuel cells, ISME J., 2008, 2, 1146.

30 C. Yang, W. Zhang, R. Liu, Q. Li, B. Li, S. Wang, C. Song, C. Qiao and A. Mulchandani, Phylogenetic diversity and metabolic potential of activated sludge microbial communities in full-scale wastewater treatment plants, Environ. Sci. Technol., 2011, 45, 7408-7415.

31 S. Jung and J. M. Regan, Comparison of anode bacterial communities and performance in microbial fuel cells with different electron donors, Appl. Microbiol. Biotechnol., 2007, 77, 393-402.

32 D. Zhang, Y. Chen, Y. Zhao and X. Zhu, New sludge pretreatment method to improve methane production in waste activated sludge digestion, Environ. Sci. Technol., 2010, 44, 4802-4808.

33 L. Bertin, C. Bettini, G. Zanaroli, S. Fraraccio, A. Negroni and F. Fava, Acclimation of an anaerobic consortium capable of effective biomethanization of mechanically-sorted organic fraction of municipal solid waste through a semi-continuous enrichment procedure, J. Chem. Technol. Biotechnol., 2012, 87, 1312-1319. 